\title{
Reflecting on the Coping with the future conference
}

\section{Hans Christian Garmann Johnsen}

The intention of the conference was to address the challenges for business and work, in the perspective of a potential systemic shift towards digitalisation and sustainability. The conference did not conclude whether we are entering a new stage in industrial development, or simply enforcing trends that are already on the way. Still, I think that the event was successful, and met the expectations that we had, in addition to giving new thoughts and ideas. It should be a good platform for further co-operation.

Some key figures: more than 100 persons attended the conference; a core group attended all three days. Some nine key notes were delivered, and some twenty papers were discussed in six session. There were several discussion sessions and two panel discussions. Researchers from several European countries as well as from the USA and South America, contributed to an international dialogue. Special issues of the three journals represented at the conference will be published.

Even though the conference did not reach conclusions or point at specifically tracks forward for the development of business and work, it did something that is not often seen in academic conferences: it brought together both practitioners and cases from practice in the form of business and policy, and from research. It also linked the theory / practice division to methodological and philosophical considerations. In the future this spectrum of considerations should be part of the debate in work life research. Also, the diversity of presentations and topics addressed in the papers and key notes could be a model for future events of this kind.

Partly included in the conference was a very interesting $\mathrm{PhD}$ defence by Carla Assuad, where the topic was the concept of rationality in relation to sustainability. It paralleled the discussion by Olav Eikeland and others in the Acton Research discussion on forms of knowledge. Work life research is under pressure to provide reliable and valid knowledge, and qualitative research in general is under pressure in the current academic and social/political climate. This calls for qualitative work life research that is based on a solid methodological foundation, and thereby an approach to Action Research that addresses some of its inherent epistemological challenges.

These three aspects of research: the dialogue between research and practice, the diversity of methodological and theoretical approaches, and the continuous awareness of the epistemological and philosophical underpinnings in the research process, are important dimensions to take forward in the further development both of AR and Workplace Innovation.

In addition, one could argue that the presentation by Emil Sobottka reminds us of the fact that research, including business research, happens within a social and political setting, with ideological dimensions that we should have a conscious relation to, not least in the perspective of sustainability. Even though these are not as much in conflict in European business development as in other parts of the world, there is conflict there, and this should be a concern for us. The key notes of Einar Duengen Bøhn and John Hurley, as well as the opening welcome address by the UoA rector Frank Reichert, emphasised the future, and a systemic dimension of the issues we discussed.

Thus, "Coping with the Future" makes it important to see the system dimensions of the context in which we are working, and address the comprehensiveness of the issues we discuss. These should be things which we bring with us in our future discussion of co-operation on how to bring work life and workplace research forward. 
I should like to thank all participants for their interesting and engaged contribution, and the organising committee for good and constructive collaboration.

\section{About the author}

Hans Christian Garmann Johnsen, Professor at University of Agder, is Managing editor EJWI and Clair of "Coping with the Future" Conference 2018. 